\title{
Specific Proposals for Innovation Teaching and Its Impact on Future Challenges for Basic Level Pupils
}

\author{
Yassir M Mahgoub $^{1}$ \\ ${ }^{1}$ Faculty of Education, University of Khartoum, Khartoum, Sudan \\ Correspondence: Yassir M Mahgoub, Faculty of Education, University of Khartoum, Khartoum, Sudan.
}

Received: June 15, 2016

Accepted: July 2, 2016

Online Published: July 11, 2016

doi:10.20849/aes.v1i2.49

URL: http://dx.doi.org/10.20849/aes.v1i2.49

\begin{abstract}
This paper primarily aims at exploring the impact of innovation teaching on future challenges for basic level pupils.

The descriptive analytical and experimental methods are used in this research. The researcher can put specific proposals for innovation teaching for basic level pupils.

The study sample consists of pupils totaling (20) pupils of the basic schools of the University of Khartoum Republic of the Sudan.

Innovation and creativity are part of the essential skills that enable students to meet with future challenges, can implement a number of tips and techniques that can help students to think creatively and find solutions for future problems.

The results showed there are significant differences between the experimental group and control group before and after the test, which confirms that students of the basic schools will be more interested in the future challenges as measured by a survey given before and after the program.

The researcher recommended the Ministry of Education should develop a plan focusing on the development of the children creative abilities of the basic level pupils, because student at this level tends to invent things or find solutions.
\end{abstract}

Keywords: innovation teaching, future challenges, basic level

\section{Introduction}

\subsection{Introduce the Problem}

Education in the arts is essential to students' intellectual, social, physical, and emotional growth and well-being. Experiences in the arts - in dance, drama, music, and visual arts - play a valuable role in helping students to achieve their potential as learners and to participate fully in their community and in society as a whole. The arts provide a natural vehicle through which students can explore and express themselves and through which they can discover and interpret the world around them. Participation in the arts contributes in important ways to students' lives and learning - it involves intense engagement, development of motivation and confidence, and the use of creative and dynamic ways of thinking and knowing. It is well documented that the intellectual and emotional development of children is enhanced through study of the arts. Through the study of dance, drama, music, and visual arts, students develop the ability to think creatively and critically. The arts nourish and stimulate the imagination, and provide students with an expanded range of tools, techniques, and skills to help them gain insights into the world around them and to represent their understandings in various ways. Study of the arts also provides opportunities for differentiation of both instruction and learning environments. Participation in the arts and learning about the arts can also broaden students' horizons in various ways. Through study of the arts, students learn about some of the diverse artistic practices, both traditional and contemporary of a variety of cultures. They learn that they are part of a living and changing culture. They also learn to appreciate the similarities and differences among the various forms of artistic expression of people around the world. The arts offer students unique opportunities to engage in imaginative and innovative thought and action and to develop the ability to communicate and represent their thoughts, feelings, and ideas in numerous ways through interacting with various works of dance, drama, music, and visual arts, including multimedia art works, students 
deepen their awareness and appreciation of diverse perspectives. They can empathize with the characters in a dance work, a drama, a song, or a visual art work, and can imagine what it would be like to be in the same situation as these people. They can identify common values, both aesthetic and human, in various works of art, and in doing so, increase their understanding of others. The arts can also encourage students to be responsible and critically literate members of society and citizens of the world. Students can learn to approach issues and present ideas and points of view in new ways and to challenge perceptions, while engaging their audience. They can explore and create original "artistic texts" in kinesthetic, visual, spatial, aural, and dramatic ways with attention to both conceptual and aesthetic considerations. Use of current and emerging technologies (e.g., video, multimedia) is integrated in the four disciplines as means of recording, enhancing, communicating, and reinterpreting ideas (The Ontario Curriculum, Ministry of Education,2009).

It is also worth mentioning that many researchers have pointed out that, through engendering a range of cross-cutting skills and abilities in learners and by motivating students to take an active participation in class, arts education is recognized as a means of achieving one of UNESCO's central educational goals: quality education. It is, therefore, critical that the arts be given a central place in all educational programs and activities, both formal and informal, with the ultimate goal of mainstreaming arts education worldwide (Shaeffer, S., 2005).

Some studies indicate the importance of visual arts in supporting students to develop visual perception (which could have an impact on literacy), although there are few studies that can yet demonstrate this. Proponents of the study of visual art as a tool for the study of visual culture suggest that this can support students to engage with, explore and critique their ideas, beliefs, values and identities, as well as the values of popular culture, society and so on. Of all the arts disciplines discussed in this review, visual arts may provide the least in terms of "conclusive" findings about the outcomes of arts learning, although qualitative and mixed-method studies provide insights into particular kinds of learning outcomes from particular kinds of visual arts learning experiences. This may be because, as outlined above, "the phrase 'visual arts' can mean any number of practices, objects, or processes" (Baker, 2002, p. 146).

\subsection{Explore Importance of the Problem}

- To recognize the importance of innovation teaching.

- The researcher is expecting to teach the subject of innovation for students in basic level.

- The researchers predict that this study enables an area for further studies to develop different strategies in the field of innovation teaching.

\subsection{Describe Relevant Scholarship}

There is also a considerable literature taking a departure point in the business economics of innovation (Tidd et al., 2005). This tends to lean on factors such as qualified demand, capacity supply, risk capital and incentive structures (Marklund et al., 2004).

\subsection{State Hypotheses and Their Correspondence to Research Design}

The study looked at two hypotheses:

- Students will learn innovation by a pre-test and posttest.

- Students will be more interested in the future challenges as measured by a survey given before and after the program.

\section{Method}

The descriptive analytical and experimental methods are used in this research. The researcher can put specific proposals for innovation teaching for basic level pupils.

\subsection{Sample Size, Power, and Precision}

The student participants will be inducting from all University of Khartoum basic schools, which have completed the basic level. Consists of (20) participants.

\subsection{Research Design}

The students were divided to two groups. This was even due to the distribution of students in these classrooms. In addition, it was discussed, who is the most creative of the students through brainstorming for two groups. Then the students had a few minutes to review the information from the summaries. The students chose who actually spoke, two students on each side. All students on the side could help on their answers as a valid measure of innovation thinking. 
The total score for the test is 10 marks and the marks were distributed as follows:

- Think creatively - Two marks.

- The imagination - Two marks.

- Problems Solving - Two marks.

- Use design tools and methods - Two marks.

- Focus on one project- Two marks.

\section{Results}

- Students have learned innovation by a pre-test and posttest.

- Students have become more interested in the future challenges as measured by a survey given before and after the program.

\subsection{Statistics and Data Analysis}

$\mathrm{T}$ test for independent data will be run to verify the equivalence of experimental and control groups after applying the test of ability and before the implementation of the program.

After the application of the program, the collected data will be analyzed by the statistical program (STATISTICAL PACKAG SOCIAL SEIENCE) (SPSS) using the appropriate statistical treatments.

\begin{tabular}{|c|c|c|c|c|c|}
\hline & & $\mathrm{N}$ & Mean & Std. Deviation & Std. Error Mean \\
\hline \multirow[t]{2}{*}{ Pair 1} & The control group & 20 & 165.85 & 29.290 & 6.550 \\
\hline & $\begin{array}{l}\text { Experimental } \\
\text { group }\end{array}$ & 20 & 186.75 & 29.563 & 6.611 \\
\hline
\end{tabular}

\section{Paired Differences}

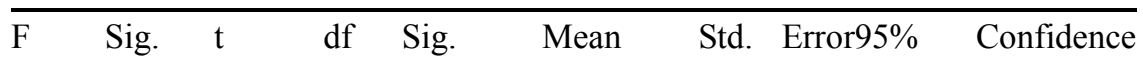
(2-tailed) Difference Difference Interval of the

Difference

\begin{tabular}{|c|c|c|c|c|c|c|c|c|c|}
\hline & & & & & & & & & \\
\hline & & & & & & & & Lower & Upper \\
\hline $\begin{array}{l}\text { Pair } \\
1\end{array}$ & $\begin{array}{l}\text { The } \\
\text { groups } \\
\text { before }\end{array}$ & two.025 & .876 & -2.24638 & .031 & -20.900 & 9.306 & -39.738 & -2.062 \\
\hline & $\&$ after & & & & & & & & \\
\hline
\end{tabular}

The validity and reliability of the instrument reported here are based on the data collected from this study. The strategy employed in the present study to test the validity and the reliability of the instrument focuses on the psychometric properties of the scales used.

Table (1) (Paired Samples Statistics) shows the internal consistency (Cronbach's alpha) of RBS and RS. As indicated by the coefficient, both instruments are reliable since the values are less than $(0.05)$.

Since the potential value $=(0.000)$ is less than $(0.05)$, it means there is significant differences between the students grades before and after the test.

Through the above tables (1-2) (Independent Samples Test) are there is a significant differences between the performance of the experimental group before and after the implementation of the program through the arithmetic mean value, which is amounted to (186.75) that is greater than the arithmetic mean value before implementing the program, amounting to (165.85).

\section{Discussion}

The main task in this model testing procedure is to determine the goodness of fit between the hypothesized 
model and the sample data. To arrive at the conclusion

Have examined the thinking skills have identified essential components such as creative thinking, critical thinking, problem solving. In this paper, arguments have been put forward that innovation has a significant role to play as far as education is concerned in basic level. If truly future challenges should be achieved, the paper has integrally argued that innovation must be incorporated into the teaching of art education.

Data scheduled and analyzed to view correlations statistics and scores. The information provided in this survey compiled and analyzed using a statistical database. The statistics and percentages compared to the hypothesis to validate or disprove the literature and scholarly writings reviewed for this study. Significance of the data will conclude that there is an indication that the hypothesis is true or false. Concentrations of the size of the differences in or correlations found will be analyzed through a multiple analysis of the variants in each of the categories of the survey sample.

Through the results, the researcher noted that the performance of students after the specific proposals for innovation teaching to enable them to think creatively skills have been shown to the researcher a large proportion of students are using imagination, problems Solving, and have appeared through the posttest.

The paper concludes with an overview of the impact of innovation teaching on future challenges for basic level

In the light of the findings, the following conclusions could be made:

The results of the study have also shown that the future challenge is achievable, and can promote innovation assessment. Later, it was also found out that it helps in solving problems provided that students and teachers are convinced of its effectiveness into the program.

In view of the findings of this study, specific proposals for innovation teaching and its impact on future challenges for basic level pupils. It is hoped that this process will not only improve think creatively, but it will also enhance future challenges for basic level pupils.

\section{Recommendation}

It is recommended that the Ministry of Education be encouraged to develop school learning and teaching plans to increase their capacity to:

1. An awareness of creative process can promote innovation among students. By problems solving and imagination. Assisting of students to critical thinking to be instrumental in scrutinizing ideas.

2. Information, programs and support for parents to gain digital skills to better assist their children's education.

3. Future research should examine whether the present findings generalize to other samples and settings.

\section{Acknowledgements}

I would like to extend thanks to the many people, in Sudan and Saudi Arabia, who so contributed in this work to presented in this article.

\section{References}

Baker, T. (2002). Reflections on visual arts education studies. In R. J. Deasy (Ed.), Critical Links: Learning in the arts and student academic and social development (pp. 145-150). Washington, DC: Arts Education Partnership.

Carlsson, B., Jacobsson, S., Holmén, M., \& Rickne, A. (2002). Innovation systems: analytical and methodological issues. Research Policy, 31, 233-245. http://dx.doi.org/10.1016/S0048-7333. (01)00138-X

Government of Ireland. (1999). Visual Arts. Mozzon Giuntina - Florence and, Officine Grafiche De Agostini Nova ra.

Grey, Anne C. (2010). No Child Left Behind In Art Education Policy: A Review of Key Recommendations For Arts Language Revisions. Arts Education Policy Review, 111(1), 8-15. http://dx.doi.org/10.1080/10632910903228132

Marklund, G., Nilsson, R., Sandgren, P., Thorslund, J. G., \& Ullström, J. (2004). The Swedish National Innovation System 1970-2003: a quantitative international benchmarking analysis. Stockholm, VINNOVA.

Shaeffer, S. Educating for Creativity: An Agenda for the 21st Century. UNESCO Asia-Pacific Regional Conference in Preparation for the World Conference on Arts Education 23 - 25 November 2005, Seoul, Republic of Korea. Retrieved from www.unesco.org/culture/lea 
The Arts. (2009). Une publication, this publication is available on the Ministry of Education's website. Queen's Printer for Ontario. Retrieved from http://www.edu.gov.on.ca.

Tidd, J., Bessant, J., \& Pavitt, K. (2005). Managing Innovation: Integrating Technological, Market and Organizational Change (3rd ed.). New York, John Wiley.

Winner, Ellen, \& Lois Hetland. (2008). Art For Our Sake School Arts Classes More Than Ever - But Not For The Reasons You Think. Arts Education Policy Review, 1109(5), 29-32. http://dx.doi.org/10.3200/AEPR.109.5.29-32

\section{Copyrights}

Copyright for this article is retained by the author(s), with first publication rights granted to the journal.

This is an open-access article distributed under the terms and conditions of the Creative Commons Attribution license (http://creativecommons.org/licenses/by/3.0/). 